\title{
Ectopic pregnancy in a patient with levonorgestrel-releasing intrauterine device in situ
}

\author{
Emel Kurtoglu*a, Haldun Arpacia ${ }^{\text {a }}$ Muzaffer Temura, Sema Gultekin ${ }^{\text {b }}$ \\ ${ }^{a}$ Gynecology and Obstetrics Department, Eregli State Hospital, Eregli, Konya, Turkey \\ ${ }^{b}$ Radiology Department, Eregli State Hospital, Eregli, Konya, Turkey
}

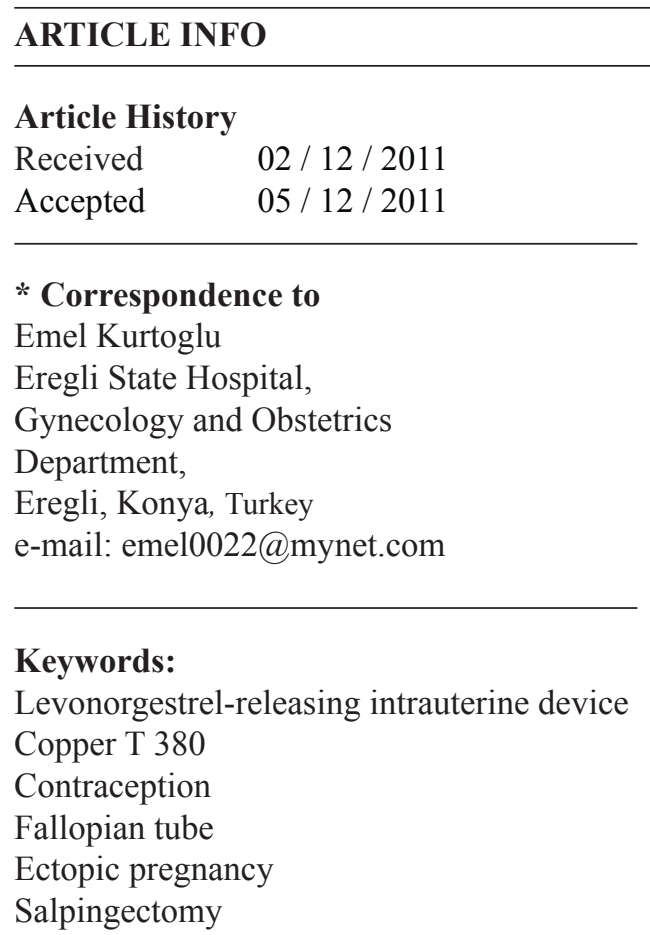

\section{ABSTRACT}

The levonorgestrel-releasing intrauterine device (LNG-IUD, Mirena) is an effective and safe contraceptive method that has many non-contraceptive benefits, such as treatment of menorrhagia and protection from pelvic inflammatory disease. However, dangerous complications, such as ectopic pregnancy, can occur with LNG-IUD use. Although the cumulative pregnancy rate with LNG-IUD is below the non-contraceptive rate, when pregnancy does occur, it is more likely to be an ectopic pregnancy. Early diagnosis and treatment are very important in order to reduce morbidity and mortality. In the case presented herein, a 35-year-old patient with an LNG-IUD in situ underwent laparoscopic salpingectomy after a diagnosis of ampullary ectopic pregnancy.

J. Exp. Clin. Med., 2012; 29:71-73

. Exp. Clin Med, $2012 ; 29: 71-73$

Department,

\section{Received $\quad 02 / 12 / 2011$}

* Correspondence to

Emel Kurtoglu

Eregli State Hospital,

Eregli, Konya, Turkey

e-mail: eme10022@mynet.com
C 2012 OMU All rights reserved

\section{Introduction}

The levonorgestrel-releasing intrauterine device (LNG-IUD) is a very effective and safe method of contraception; the cumulative pregnancy rate at five years is $<0.5 \%$ (Kailasam and Cahill, 2008). While it has potential non-contraceptive benefits for some gynaecologic problems, such as fibroids, menorrhagia, and endometriosis, there are also complications, such as perforation, bleeding, and ectopic pregnancy (Kailasam and Cahill, 2008). The ectopic pregnancy rate is 0.02 per 100 woman-years, and it is the most dangerous complication of LNG-IUD (Mikkelsen et al., 2010). The overall risk is about one in 1,000 over the course of five years. When a pregnancy is detected with an LNG-IUD in situ, the risk of ectopic pregnancy is about one in 20 , so very special attention is needed; however, previous ectopic pregnancy is not a contraindication for using the LNG-IUD (Kailasam and Cahill, 2008). Here, we described one of these rare cases of ectopic pregnancy in a 35-year-old woman who had an ampullary ectopic pregnancy with LNG-IUD.

\section{Case}

A 35-year-old woman presented with abdominal pain and vaginal bleeding. The patient had a history of progressive abdominal pain in her right lower abdominal quadrant, irregular vaginal bleeding, and nausea for five days. She had been using a levonorgestrel-releasing intrauterine device for four months, which was removed by the gynaecologist after the diagnosis of ectopic pregnancy. The patient did not remember the date of her last menstrual period. She had had three vaginal deliveries. She did not have a history of abortion, ectopic pregnancy, pelvic inflammatory disease, or previous tubaluterine surgery, and she did not smoke.

On physical examination, the patient's blood pressure was $90 / 50 \mathrm{~mm} \mathrm{Hg}$, her heart rate was 110 beat $/ \mathrm{min}$, and she was afebrile. There was rebound tenderness and guarding in her right lower abdominal quadrant and slight tenderness in the other quadrants. Laboratory findings were: quantitative human chorionic gonadotropin (hCG) level above 1000 $\mathrm{mIU} / \mathrm{ml}$, hemoglobin $9.8 \mathrm{~g} / \mathrm{dl}$, and white cell blood count $6.2 \times 10^{\prime} 9 / \mathrm{L}$. A gestational sac located in the ampullary of 
the right fallopian tube contained an embryo measuring 17.4 $\mathrm{mm}$, with positive heart rate $(172 \mathrm{beat} / \mathrm{min})$, consistent with an 8-week, 1-day pregnancy (Fig. 1 and 2).

Thickness in the wall of the right fallopian tube, with free fluid around the tube, were visualised during a transvaginal sonographic examination (Fig. 3).

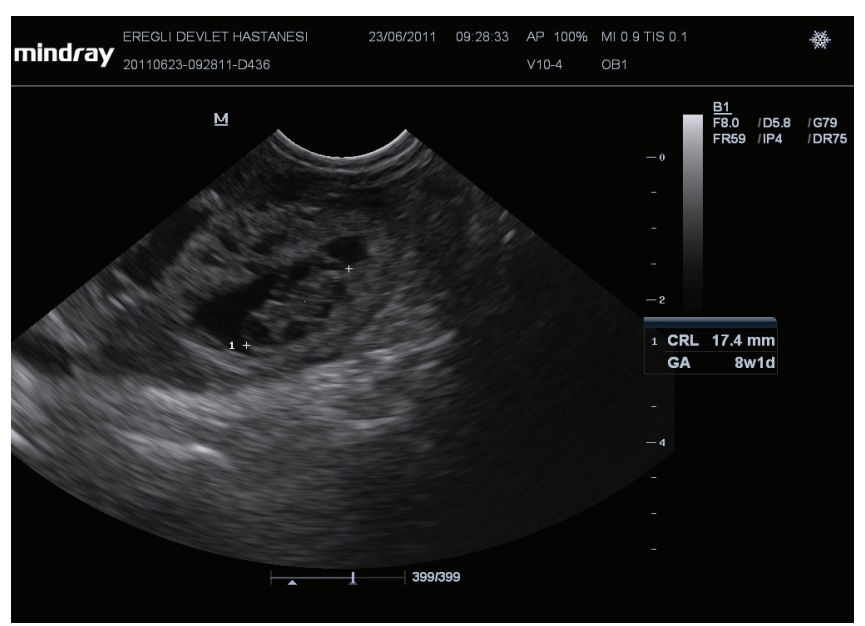

Fig. 1. Transvaginal ultrasonography of right ampullary ectopic pregnancy

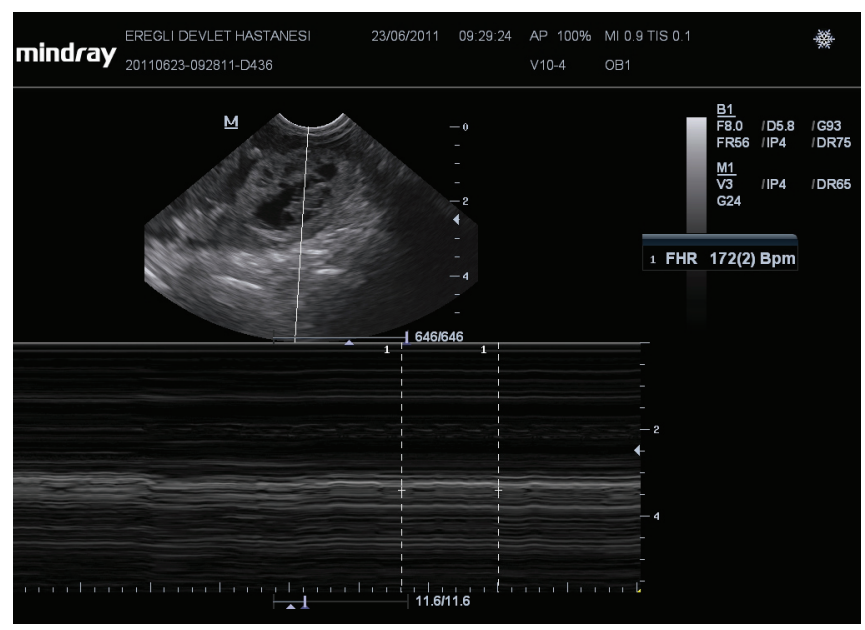

Fig. 2. 8-week and 1-day embryo with heart rate of 172 beat $/ \mathrm{min}$

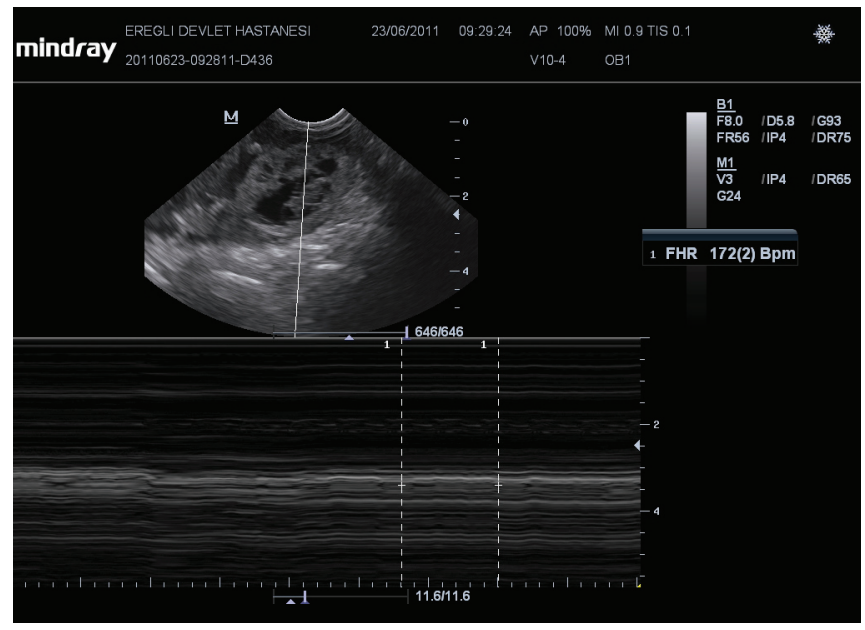

Fig. 3. Thickness of the fallopian tube wall and peritubal free fluid
After informed consent, the patient underwent laparoscopic surgery; a right salpingectomy and left tubal ligation were performed. There was no postoperative complication, and the patient was discharged from hospital on the next postoperative day.

\section{Discussion}

Ectopic pregnancy is one that occurs outside the uterine cavity, usually on the adjacent side and generally located in the fallopian tube. In more than $98 \%$ of ectopic pregnancies, the primary site is in the fallopian tube, and $80 \%$ of those occur in the ampullary region (Cahill and Wardle, 2007). The current rate of ectopic pregnancy (ectopic pregnancy per 1,000 pregnancies) in the United Kingdom is 11.1, and in the United States it is 20 (Cahil and Wardle, 2007).

The most common risk factors are previous pelvic surgery, history of ectopic pregnancy or pelvic inflammatory disease, smoking, induction of ovulation, and use of intrauterine devices (IUDs) (Malinowski and Bates, 2006). With increasing worldwide use of IUDs, the relationship between ectopic pregnancy and IUDs has been attracting more attention, especially pregnancies occurring with LNG-IUD (Bednarek and Jensen, 2009).

When IUD-using contraceptors and non-contraceptors are compared, the absolute number of ectopic pregnancies in IUD-using contraceptors is lower, because total pregnancy rate in IUD users is lower (Bednarek and Jensen, 2009). In an analysis of 42 randomised trials, ectopic pregnancy rates were 1.2-1.6 per 100 woman-years for women not using contraception; however, the ectopic rates were 0.5 for Copper IUD and 0.2 for LNG-IUD per 1,000 woman-years (Andersson et al., 1994). In a study by Turok et al. (2010)regarding the operative management of IUD complications, ectopic pregnancy was the most common diagnosis among pregnant women (23 of 42 pregnant women, 54.8\%). Different results have been found in studies comparing the prevalence of ectopic pregnancies in women using Copper T 380 and LNG-IUD (Luukkainen et al., 1987; Sivin et al., 1990).

One of these studies was an international comparative study between LNG-IUD and Copper-T 380 in a five-year follow up (Sivin et al., 1990). Results showed that none of six pregnancies among 1.124 women were ectopic with the LNG-IUD, while two ectopic pregnancies occurred in 1.121 women using Copper T 380 (Sivin et al., 1990).

In another study, Luukkainen et al. (1987) compared the $20 \mathrm{mcg} /$ day levonorgestrel-releasing intrauterine device (LNG-20) with the Copper-releasing IUD (Nova T) after one year of use. There was only one pregnancy, which was intrauterine, in LNG-20 users ( $\mathrm{n}=1821)$, while one of eight pregnancies occurring in the Nova $\mathrm{T}$ users $(\mathrm{n}=937)$ was ectopic (Luukkainen et al., 1987).

One of the limited studies on LNG-IUD and ectopic pregnancy was by Backman et al. (2000). They evaluated 17,360 women using LNG-IUD and reported 44 ectopic pregnancies among 108 pregnancies that occurred (Backman et al., 2000).

Knowing the site of ectopic pregnancies with IUDs is important for treatment and follows up. The ampullary region of the fallopian tube has been reported as the most common site of ectopic pregnancy, as in our case; however, a cornual 
pregnancy as a complication of the use of LNG-IUD has been reported in the literature (Beltman and Groot, 2009).

Many factors affect the decision treatments made by a physician. In our case, a non-ruptured, 8-week, 1-day pregnancy with positive fetal heart rate required surgical treatment. However, medical treatment with methotrexate can be used in special situations (Beltman and Groot, 2009).

This case report is about one of the rare ectopic pregnancies with LNG-IUD use. As pregnancies that occur with LNGIUD are more likely to be ectopic, more attention is required for early diagnosis and reduction in morbidity and mortality.

\section{REFERENCES}

Andersson, K., Odlind, V., Rybo, G., 1994. Levonorgestrel releasing and copper releasing (Nova T) IUDs during five years of use: A randomized comparative trial. Contraception. 49, 56-72.

Backman, T., Huhtala, S., Blom, T., 2000. Length of use and symptoms associated with premature removal of the levonorgestrel intrauterine system: A nation-wide study of 17.360 users. B.J.O.G. 107, 335-339.

Bednarek Paula, H., Jensen Jeffry, T., 2009. Safety, efficacy and patient acceptability of the contraceptive and non-contraceptive uses of the LNG-IUS. Int. J. Woman's Health. 1, 45-58.

Beltman, J.J., Groot, C.J.M., 2009. Cornual pregnancy as a complication of the use of a levonorgestrel intrauterine device: A case report. J. Med. Case Reports. 3, 8387.

Cahill, P. D. J., Wardle, P. G., 2007. Bleeding and pain in early pregnancy. In high risk pregnancy management options, third edition. D. K. James, P. J. Steer, C. P. Weiner, B. Gonik, eds. Sounders Elsevier, U.S.A, 91-96.

Kailasam, C., Cahill, P. D. J., 2008. Review of the safety, efficacy and patient acceptability of the levonorgestrel-releasing intrauterine system. Patient Prefer Adherence. 2, 293-302.

Luukkainen, T., Allonen, H., Haukkamaa, M., Holma, P., Pyorala, T., Terho, J., Toivonen, J., Batar, I., Lampe, L., Andersson, K., 1987. Effective contraception with the levonorgestrel-releasing intrauterine device: 12-month report of a European multicenter study. Contraception. 36, 169-179.

Malinowski, A., Bates, S.K., 2006. Semantics and pitfalls in the diagnosis of corneal-interstitial pregnancy. Fertil. Steril. 86, 1764.

Mikkelsen, M.S., Hqjgaard, A., Bor, P., 2010. Extrauterin pregnancy with gestagen-releasing intrauterine device in situ. Ugeskr Laeger. 172, 1304-1305.

Sivin, I., el Mahgoub, S., McCarthy, T., Mishell, D.R.Jr., Shoupe, D., Alvarez, F., Brache, V., Jimenez, E., Diaz, J., Faundes, A., 1990. Long-term contraception with the levonorgestrel $20 \mathrm{mcg} /$ day (LNG 20) and the Copper T $380 \mathrm{Ag}$ intrauterin devices: A five year randomized study. Contraception. 42, 361-367.

Turok, D.K., Gurtcheff, S.E., Gibson, K., Handley, E., Simonsen, S., Murphy, P.A., 2010. Operative management of intrauterine device complications: A case report series. Contraception. 82, 354-357. 